\title{
Generating Set Search Method with Optimal Bind Tolerance for Solving the Economic Load Dispatch Problem of Thermal Stations
}

This paper was downloaded from TechRxiv (https://www.techrxiv.org).

\section{LICENSE}

CC BY 4.0

SUBMISSION DATE / POSTED DATE

$30-06-2021 / 10-07-2021$

\section{CITATION}

Onyegbadue, Ikenna; Ogbuka, Cosmas; Madueme, Theophilus (2021): Generating Set Search Method with Optimal Bind Tolerance for Solving the Economic Load Dispatch Problem of Thermal Stations. TechRxiv. Preprint. https://doi.org/10.36227/techrxiv.14885220.v1

$\mathrm{DOI}$ 


\title{
Generating Set Search Method with Optimal Bind Tolerance for Solving the Economic Load Dispatch Problem of Thermal Stations
}

\author{
I. A. Onyegbadue, C. U. Ogbuka and T. C. Madueme
}

\begin{abstract}
A non-derivative direct search approach called Generating Set Search (GSS) algorithm with varying bind tolerance to solve non-convex Economic Load Dispatch problem of the thermal stations in Nigeria is presented. A complete poll was carried out with initial mesh size of 1.0, expansion factor of 2.0 and contraction factor of 0.5 . The binding tolerance was varied from $100-2200$ with an increment of 100 . The stopping criteria were based on the following: mesh tolerance of 0.000001 , maximum iteration of 1500 and maximum function evaluation of 30000 . The Economic Load Dispatch of $2500 \mathrm{MW}, 3000 \mathrm{MW}, 3500 \mathrm{MW}$ and $4000 \mathrm{MW}$ produced optimal solutions at binding tolerances of 500, 600,1100 , and 1600 respectively. The economic cost (measured in quantity of fuel) obtained for the dispatch of $2500 \mathrm{MW}, 3000 \mathrm{MW}$, $3500 \mathrm{MW}$ and $4000 \mathrm{MW}$ were 83577.6936190168 MMBTU/hr, 83577.6936667599 MMBTU/hr, 83577.6937160183 MMBTU/hr and 83577.694264612 MMBTU/hr respectively. The evaluations carried out on the function in order to obtain the best solution were 1484, 5709, 6895 and 7556 for $2500 \mathrm{MW}, 3000 \mathrm{MW}, 3500 \mathrm{MW}$ and $4000 \mathrm{MW}$ of load respectively. Although the optimal bind tolerances had more iterations and evaluations, these can be traded off for the best solutions offered.
\end{abstract}

Index Terms-- Generating Set Search, Binding Tolerance, Optimization and Economic Load Dispatch.

\section{INTRODUCTION}

$\mathrm{E}^{\mathrm{c}}$ conomic Load Dispatch (ELD) has received significant attention in recent years for its vital role in the power system operation and planning [1]. ELD aims to schedule the committed generating unit outputs to simultaneously minimize the operating cost and meet the load demand of a power system while satisfying all the equality and inequality constraints $[2$, 3]. ELD problem is non-linear with linear constraints and boundary conditions [4]. Conventional optimization techniques, commonly referred to as traditional optimization techniques have been previously used to solve the ELD problem [5, 6]. Lambda-iteration method, Gradient method, Base-point participation factor method are traditional methods adopted to solve the ELD problem [7].The solutions from these methods get stuck at local minima after a long computation time [8]. The fuel cost function in the traditional ELD problem, is modelled by a quadratic function. This problem can thus be transformed into a classical convex problem [9]. With the restriction introduced by the valve point effect and prohibited operating zones in the actual power system, the traditional cost function becomes non-convex and thus becomes difficult to optimize using traditional methods [10]. With the expansion of the power grid and the increase of the constraint variables, a traditional mathematical programming method is prone to the problem of dimensionality disaster [10]. In order to overcome some drawbacks of the traditional methods, many meta-heuristic based optimization algorithms have been developed. Simulated Annealing (SA) was implemented in ELD problems and produced nearly optimal solutions in the early 1990s [11]. Then evolutionary based algorithms were used for solving ELD problem. Genetic Algorithm (GA) and its improved versions have been widely used [12]. Tabu Search (TS), Particle Swarm Optimization (PSO), Differential Evolution (DE), Simulated Annealing (SA) are other heuristic search algorithms proven to be effective when applied to ELD [13]. Some of these heuristic methods have good exploration capability but poor exploitation capability and vice versa. To provide a proper balance between exploration and exploitation the researchers are steered towards hybrid algorithms [14]. Hybrid algorithms such as hybridized simplex search method with fuzzy adaptive particle swarm optimization (FAPSO-NM) method, hybridization of differential evolution (DE) with Biogeography-based optimization (DE/BBO), parallel hybrid algorithm (DPD) which combines DE with PSO and hybrid GA with DE and pattern search (PS) (GA-DE-PS) have been developed to solve ELD problem [14]. Even though all of these algorithms produce good solutions and have some advantages, each method has its own limitations. Despite the numerous studies carried out to solve ELD problems, there is the need for a better algorithm that will yield a global result.

Generating set search (GSS), is part of feasible-point methods for derivative-free optimization that evaluates a set of trial points to see if any has a lower function value than the current iteration [15]. GSS is an exploitation algorithm that is

Ikenna A. Onyegbadue is with the Department of Electrical and Computer Engineering, Igbinedion University Okada, (e-mail: onyegbadue.ikenna@iuokada.edu.ng).

Cosmas U. Ogbuka, is with the Department of Electrical Engineering and Africa Centre of Excellence for Sustainable Power and Energy Development (ACESPED), University of Nigeria, Nsukka (e-mail: cosmas.ogbuka@unn.edu.ng).

Theophilus C. Madueme is with the Department of Electrical Engineering, University of Nigeria, Nsukka, (e-mail: theophilus.madueme@unn.edu.ng). 
suited global optima points [16]. Generating set search method solves optimization problems without recourse to the gradient of the problem. GSS algorithm searches a set of points around a particular current point with the aim of finding a point that will produce a minimum value than the current point. GSS method can obtain global optima for a non-smooth cost function [17].

This study is aimed at solving Economic Load Dispatch problem of thermal stations using Generating set search method. The specific objectives are viz: (i) to obtain optimal solution to ED problem of thermal stations by varying bind tolerance value of GSS algorithm. (ii) to evaluate the performance of the solutions obtained and hence find an optimal bind tolerance that solves the Economic Load Dispatch problem.

Bind tolerance specifies the tolerance for the distance from the current point to the boundary of the feasible region with respect to linear constraints. It specifies when a linear constraint is active $[18,19]$.

\section{MATHEMATICAL FoRMULATION}

Economic Load Dispatch problem can be formulated thus;

Min $F=\sum_{i=1}^{n} f_{i}\left(P_{i}\right)$

$F=\sum_{i=1}^{n}\left(a_{i} P_{i}^{2}+b_{i} P_{i}+c\right) \quad \mathrm{BTU} / \mathrm{hr}$

$\forall f: \mathfrak{R}^{n} \rightarrow \mathfrak{R}$

Subject to;

$P_{\min } \leq P \leq P_{\max }$ (Bound constraint)

$M P=v \quad$ (Equality Constraint)

$P \in T$; where $\mathrm{T}$ is a feasible region.

Generating set search algorithm uses bind tolerance to specify locally active constraints. A working set $D(P, \varepsilon)$ is developed by considering values the constraints and bind tolerance $\varepsilon$.

The working set can be represented thus;

$D(P, \varepsilon)=\left\{i \in\{1, \ldots z\} \mid \frac{m_{i}^{T} P-v_{i}}{\left\|m_{i}\right\|} \leq \varepsilon\right\}$

Where;

$m_{i}^{T}$ is the ith row of matrix M (equality constraint)

$v_{i}$ is the ith component of vector

A. Algorithm for Linearly Constrained Generating Set Search Method

Let;

$f: \mathfrak{R}^{n} \rightarrow \mathfrak{R}$ be given for the Economic Load Dispatch problem. T defines the feasible region.

$P_{0} \in T$ represents the start guess.

$\Delta_{t o l}>0$ be the step-length convergence tolerance
$\Delta_{0}>\Delta_{\text {tol }}$ be the start value of the step-length control parameter

$\phi_{\max } \geq 1$ be the upper bound on the expansion factor

$\theta_{\max }<1$ be an upper bound on the contraction factor

$\varepsilon>0$ be the bind tolerance for locally active constraints

For the iteration $\mathrm{w}=1,2, \ldots$;

a. Let $D_{w}=G_{w} \cup H_{w}$ where $D_{w}$ represents the set search direction, $G_{w}$ is the generating unit for the set search direction which satisfies $\beta_{\text {min }} \leq\|d\| \leq \beta_{\text {max }} \cdot \beta_{\text {min }}$ and $\beta_{\text {max }}$ are the bound constraints for the generating unit. The element $d$ is a member of sets $G_{w}$ and $H_{w}$.

b. If there exist $d_{w} \in D_{w}$ such that $f\left(P_{w}+\Delta_{w} d_{w}\right) \geq f\left(P_{w}\right)-\rho\left(\Delta_{w}\right)$ and

$P_{w}+\Delta_{w} d_{w} \in T$, then carryout the following;

Set $P_{w+1}=P_{w}+\Delta_{w} d_{w}$

Set $\Delta_{w+1}=\phi_{w} \Delta_{w}$, where $1 \leq \phi_{w} \leq \phi_{\max }$

$\forall w \in S \quad$ ( $S$ is a set of successful poll).

$\rho\left(\Delta_{w}\right)$ allows the possibility of enforcing sufficient decrease on the function (f) by establishing a threshold for the amount of decrease that must be realized for the iteration to be deemed a success.

c. If step b is not feasible, then the following should be done:

Set $P_{w+1}=P_{w}$

Set $\Delta_{w+1}=\theta_{w} \Delta_{w}$ where $0<\theta_{w}<\theta_{\max }<1 \quad \forall w \in U$ (

$U$ is a set of unsuccessful poll).

If $\Delta_{w+1}<\Delta_{t o l}$, terminate the algorithm.

\section{Methodology}

The optimal Economic Load Dispatch solutions at different bind tolerance is obtained using GSS algorithm from optimization toolbox. The number of iterations, number of function evaluations and the best solution for the minimized function were obtained for varying bind tolerance ( $\varepsilon \mid \varepsilon=100 a, \exists a \in \mathrm{N}, 1 \leq a \leq 22$ ). A complete poll was carried out with initial mesh size of 1.0, expansion factor of 2.0 and contraction factor of 0.5 . The stopping criteria were based on the following; mesh tolerance of 0.000001 , maximum iteration of 1500 and maximum function evaluation of 30000 . Four different loading schemes were used for this study viz; 2500 MW, 3000 MW, 3500 MW and 4000 MW. Table SM1 shows fuel cost coefficients for thermal generators in Nigeria. 


\section{RESULTS AND DISCUSSIONS}

\section{A. Dispatch of $2500 \mathrm{MW}$}

Figures SM1 and SM2 show the graph of the function value and total function evaluations respectively for the best solution. The optimal solution was found at binding tolerance 500 .

\section{B. Dispatch of $3000 \mathrm{MW}$}

Figures SM3 and SM4 show the graph of the function value and total function evaluations respectively for the best solution. The optimal solution was found at binding tolerance 600 .

\section{Dispatch of $3500 \mathrm{MW}$}

Figures SM5 and SM6 show the graph of the function value and total function evaluations respectively for the best solution. The optimal solution was found at binding tolerance 1100 .

\section{Dispatch of $4000 \mathrm{MW}$}

Figures SM7 and SM8 show the graph of the function value and total function evaluations respectively for the best solution. The optimal solution was found at binding tolerance 1600 .

Table SM2 is a summary table containing optimal fuel quantity for varying binding tolerance and dispatched load.

From Table SM2, the best solution obtained for the dispatch of $2500 \mathrm{MW}$ load was 83577.6936190168 MMBTU/hr with a binding tolerance of 500 . The dispatch of $3000 \mathrm{MW}$ produced best solution of $83577.6936667599 \mathrm{MMBTU} / \mathrm{hr}$ with a binding tolerance of 600 . The best solution obtained for the dispatch of $3500 \mathrm{MW}$ load was 83577.6937160183 MMBTU/hr with a binding tolerance of 1100 . The best solution obtained for the dispatch of $4000 \mathrm{MW}$ load was 83577.694264612 MMBTU/hr with a binding tolerance of 1600 .

Table SM3 shows the total evaluations carried out on the objective function for the various dispatched load and varying bind tolerance.

From Table SM3, the total number of evaluations carried out on the objective function to obtain the best solution for 2500 MW, $3000 \mathrm{MW}, 3500 \mathrm{MW}$ and $4000 \mathrm{MW}$ of dispatched load were 1484, 5709, 6895 and 7556 respectively.

The total iteration encountered during the evaluation of the objective function is represented in Table SM4.

From Table SM4, the total number of iterations carried out to obtain the best solution for $2500 \mathrm{MW}, 3000 \mathrm{MW}, 3500 \mathrm{MW}$ and $4000 \mathrm{MW}$ of dispatched load were 88, 292, 348 and 358 respectively.

Figures SM9 to SM12 show the optimal dispatch solutions for $2500 \mathrm{MW}, 3000 \mathrm{MW}, 3500 \mathrm{MW}$ and $4000 \mathrm{MW}$.

For Figures SM9 to SM12, the key 1, 2, 3, 4, 5, 6, 7, 8, 9, 10, 11, 12, 13, 14, and 15 are for Afam (VI), Sapele NIPP, Afam (I-V), Olorunsogo NIPP, Olorunsogo Gas, Delta Gas, Omotosho Gas, Omotosho NIPP, Geregu gas, Geregu NIPP. Okpai, Alaoji, Ihovbor, Egbin, and Sapele Steam respectively.

\section{CONCLUSION}

This paper has presented a new approach to solve ELD problem of thermal stations in Nigeria with the Generating Set Search algorithm by varying the binding tolerance parameter.
The performance characteristics curves for varying binding tolerances have been plotted using number of Iteration, total cost values and total evaluations. Four different loading schemes were used for this study viz; $2500 \mathrm{MW}, 3000 \mathrm{MW}$, $3500 \mathrm{MW}$, and $4000 \mathrm{MW}$. For the $2500 \mathrm{MW}$ loading scheme, the optimal solution was reached at a binding tolerance of 500 . The Economic Load Dispatch of $3000 \mathrm{MW}, 3500 \mathrm{MW}$ and $4000 \mathrm{MW}$ of load produced optimal solutions at binding tolerances of 600,1100 and 1600 respectively. The economic cost (measured in quantity of fuel) obtained for the dispatch of $2500 \mathrm{MW}, 3000 \mathrm{MW}, 3500 \mathrm{MW}$ and $4000 \mathrm{MW}$ were 83577.6936190168 MMBTU/hr, 83577.6936667599 MMBTU/hr, 83577.6937160183 MMBTU/hr, and 83577.694264612 MMBTU/hr respectively. The total number of evaluations carried out on the function in order to obtain the best solution were 1484, 5709, 6895 and 7556 for $2500 \mathrm{MW}$, $3000 \mathrm{MW}, 3500 \mathrm{MW}$ and $4000 \mathrm{MW}$ of load respectively. Although the optimal bind tolerances had more iterations and evaluations, these can be traded off for the best solutions offered.

\section{REFERENCES}

[1] X. Guojiang, Z. Jing, Y. Xufeng, S. Dongyuan, H. Yu, Y. Yao and C. Gonggui, "A Novel Method for Economic Dispatch with Across Neighborhood Search: A Case Study in a Provincial Power Grid, China," Hindawi Complexity, vol. 2018, pp. 1-18, 2018.

[2] M. Nwohu and O. P. Osaremwinda, "Evaluation of Economic Load Dispatch Problem in Power Generating Stations by the Use of Ant Colony Search Algorithms," International Journal of Research Studies in Electrical and Electronics Engineering (IJRSEEE), vol. 3, no. 1, pp. 20-29, 2017.

[3] N. R. H. Abdullah, G. Norazizah, I. Norshafiqah, F. S. Nadiatul, S. Rosdiyana, M. Mahfuzah and P. Dwi, "SOLVING ECONOMIC DISPATCH (ED) PROBLEM USING ARTIFICIAL IMMUNE SYSTEM, EVOLUTIONARY PROGRAMMING AND PARTICLE SWARM OPTIMIZATION," ARPN Journal of Engineering and Applied Sciences, vol. 11, no. 10, pp. 6663-6667, 2016.

[4] P. Li, S. Jun and C. Qidong, "Solving Power Economic Dispatch Problem with a Novel Quantum-Behaved Particle Swarm Optimization Algorithm," Mathematical Problems in Engineering, vol. 2020, pp. 1-11, 2020.

[5] V. K. Abanihi, P. I. Ezomo, D. Aliu, P. U. Chinedu, J. A. Obari and M. O. Momoh, "Complementarity Problem Approach to Economic Power Dispatch of Nigeria Power System," JOURNAL OF SCIENCE TECHNOLOGY AND EDUCATION, vol. 8, no. 2, pp. 240-249, 2020.

[6] S. O. Okozi, G. C. Ogbonna, M. Olubiwe and E. O. Ezugwu, "Solution to the Economic Dispatch Problem of the Nigerian Power System using Genetic Algorithm," Nigerian Journal of Technology (NIJOTECH), vol. 38, no. 4, p. 1036 -1047, 2019. 
[7] B. Swaraj and S. Dipu, "Comparative Analysis of Jaya Optimization Algorithm for Economic Dispatch

Solution," International Journal for Research in Applied Science \& Engineering Technology (IJRASET), vol. 5, no. 8, pp. 909-922, 2017.

[8] J. N. Ndunagu, V. K. Abanihi and S. Ikheloa, "ECONOMIC LOAD DISPATCH OF NIGERIAN POWER NETWORK USING A HYBRID OF EVOLUTIONARY PROGRAMMING AND EFFICIENT PARTICLE SWARM OPTIMIZATION," FUW Trends in Science \& Technology Journal, vol. 4, no. 3, pp. 697-702, 2019.

[9] F. Chao, Z. Suqi and C. Kuei-Hsiang, "Energy Management of a Power System for Economic Load Dispatch Using the Artificial Intelligent Algorithm," Electronics, vol. 9, no. 1, 2020.

[10] K. Sarker, B. Roy, J. Sarker and D. Santra, "A solution procedure to the economic load dispatch problem through the gravitational search technique," International Journal of Engineering, Science and Technology, vol. 11, no. 1, pp. 10-21, 2019.

[11] G. Ugur, D. Serhat, S. Yusuf, H. T. Kahraman and M. K. Dosoglu, "Symbiotic Organisms Search algorithm for economic load dispatch problem with valve-Symbiotic Organisms Search algorithm for economic load dispatch problem with valve-point effect," Scientia Iranica, vol. 25, pp. 3490-3506, 2018.

[12] S. Katoch, S. Chauhan and V. Kumar, "A review on genetic algorithm: past, present, and future," Multimedia Tools and Application, vol. 80, p. 8091-8126, 2021.

[13] A. Barliarsingh, "Economic Load Dispatch Falicitating Moderate Random Search PSO," International Refereed Journal of Engineering and Science., vol. 6, no. 9, pp. 512, 2017.

[14] K. Mohit and J. Dhillon, "Hybrid Artificial Algae Algorithm for Economic Load Dispatch," Applied Soft Computing Journal, vol. 71, pp. 89-109, 2018.

[15] J. Larson, M. Menickelly and S. M. Wild, "Derivativefree optimization methods," Acta Numerica, vol. 28, p. 287-404, 2019.

[16] K. Dae-Woo, P. Gyeong-Jae, L. Ji-Han, K. Jong-Wook, K. Yong-Jae and J. Sang-Yong, "Hybridization Algorithm of Fireworks Optimization and Generating Set Search for Optimal Design of IPMSM," IEEE Transactions on Magnetics, vol. 53, no. 6, pp. 1- 4, 2017.

[17] B. H. Enrique and R. P. José, "A Direct Search Algorithm for Global Optimization," Algorithms, vol. 9, no. 40, pp. 1-22, 2016.

[18] "Pattern Search option," MathWorks, [Online]. Available: https://www.mathworks.com/help/gads/pattern-searchoptions.html. [Accessed 26 May 2021].

[19] "Genetic Algorithm and Direct Search Toolbox for use with MATLAB," 2004. [Online]. Available: http://cda.psych.uiuc.edu/matlab_pdf/gads_tb.pdf. [Accessed 26 May 2021]. 